\title{
CONTINUUM ENTRE DOS FORMACIONES DISCURSIVAS: DEL DISCURSO TRADICIONAL AL DISCURSO NEOLIBERAL SOBRE SER PROFESOR
}

\author{
Continuum Between two Discursive Formations: \\ From Traditional Discourse to Neoliberal Discourse about Being a Teacher \\ Lariza Elvira Aguilera Ramírez \\ Ernesto de los Santos Domínguez \\ Escuela Normal Superior "Profr. Moisés Sáenz Garza"
lariaguilera_ens@yahoo.com.mx
sandernesto57@gmail.com
}

\section{Resumen:}

En la formación de docentes la fuerza del interdiscurso confronta dos formaciones discursivas (FD): La FD neoliberal de la educación coexiste con el FD de la educación tradicional que construye una imagen del profesor como sacerdote-apóstol acuñada en la modernidad. Analizamos en el discurso normalista estudiantil (México) lo que puede y debe ser dicho en la coyuntura, la forma en que la ideología y el poder se materializan en el discurso, la expresión de opciones políticas divergentes que representan las formaciones ideológicas de las que se desprenden campos de podersaber que configuran al sujeto del discurso: el normalista, futuro profesor.

\section{Palabras clave:}

Práctica discursiva, formación discursiva, formación ideológica, formación de docentes, ser profesor.

\begin{abstract}
:
In the training of teachers the strength of interdiscourse confronts two discursive formations (FD): The neoliberal FD of education coexists with the FD of traditional education that builds an image of the teacher as a priestapostle coined in modernity. We analyze in the student normalist discourse (Mexico) what can and should be said in the conjuncture, the way in which ideology and power materialize in the discourse, the expression of divergent political options that represent the ideological formations of which fields of power-knowing that shape the subject of discourse: the normalist, future teacher.
\end{abstract}

\section{Keywords:}

Discursive practice, Discursive Formation, Ideological Formation, Teacher Training, Being a teacher. 
Recibido: 18/03/2018

Aceptado: 06/06/2018

\section{INTRODUCCIÓN}

El reconocimiento de la racionalidad que funda la emergencia de ser profesor como un objeto discursivo fue posible al usar como apoyo teórico a Foucault (1996) en lo que respecta al poder pastoral; de su estudio se desprenden las notas constitutivas del objeto discursivo central en esta investigación.

En la ruta analítica del estudio de la ideología y el poder recurrimos a los aportes de Bauman (2007) y Laval y Dardot (2013) con el propósito de estudiar el fenómeno global, la racionalidad neoliberal y su incidencia en la educación, articulado con la teoría de Pêcheux (1978) acerca de las formaciones socio-ideológico discursivas que inciden en los imaginarios de los sujetos. En esta misma línea consideramos los aportes de Foucault (2006).

El estudio aborda específicamente el discurso de estudiantes normalistas del estado de Nuevo León, México. El corpus de análisis son transcripciones de entrevistas a 30 alumnos de la Licenciatura en Educación Secundaria durante el último año de formación. Se llevó a cabo la lectura completa de las entrevistas, se seleccionaron los segmentos asociados a la problemática del estudio y se analizaron las secuencias discursivas elaboradas por los informantes. Presentamos, a manera de ilustración, segmentos retomados de entrevistas con alumnos normalistas; destacamos en negritas los pasajes que sirven para ilustrar la aplicación de la teoría.

\section{FORMACIÓN SOCIAL, FORMACIÓN IDEOLÓGICA: SER PROFESOR EN LA GLOBALIZACIÓN/SOCIEDAD NEOLIBERAL}

La educación y la formación de profesores se realiza en nuestros tiempos, en el marco de condiciones sociales, económicas y culturales que instauran una racionalidad que incide en la conformación de los sujetos, en su identidad personal, cultural y profesional. Los elementos de esta demarcación los abordamos con base en las propuestas de Pêcheux Haroche y Henry (1971, en Haidar, 2006), en relación con las categorías de formación social, formación ideológica y formación discursiva. El planteamiento general es el siguiente: En una formación social (política, histórica y cultural) genera una formación ideológica constituida por ideologías que responden a diversos intereses, que incide en la forma en que son elaborados y definidos los objetos discursivos. En una Formación discursiva se articulan una o varias practicas discursivas que se generan a partir de lo que puede y debe decirse, los sujetos que pueden hacer uso de la palabra y la modalidad de los enunciados, así como las formas de censura que serán adoptadas; de esa manera, en la lengua se hacen patentes las diferentes manifestaciones ideológicas que les corresponden. Así la formación discursiva es el origen de la producción de sentido.

En la globalización se instaura una forma de estructuración y organización social: la racionalidad neoliberal "se puede definir como el conjunto de los discursos, de las prácticas, de los dispositivos que determinan un nuevo modo de gobierno de los 
hombres según el principio universal de la competencia" (Laval y Dardot, 2013: 15). Así, la razón neoliberal atraviesa las prácticas de los seres humanos, "La familia, el matrimonio..., la acción colectiva, la decisión política, la legislación, se convierten en objetos del razonamiento económico" (Laval y Dardot, 2013: 216)

La educación institucionalizada, si bien conserva rasgos de la escuela moderna, es conminada para transformarse y así continuar con el proyecto de ideologización que inicialmente se le había encomendado. Según Puiggrós (1996), los sistemas educativos iniciaron el proceso de reforma a partir de la segunda mitad del siglo XX, con base en el argumento de que la educación pública fracasó al no rendir los resultados esperados, ser inequitativa e ineficiente.

Esta formación social genera una formación ideológica, en la que coexisten ideologías diversas, entre las cuales una de ellas es la hegemónica que es elaborada y difundida por la clase dominante en una sociedad. La hegemonía favorece la difusión de creencias, la cultura y la moral, mediante las instituciones; la clase en el poder se sirve de éstas para llevar a cabo un proceso de legitimación, de tal manera que se interna en la subjetividad de los sujetos y, por lo tanto, en sus prácticas y en su identidad, para que realicen las acciones convenientes a partir de la visión que han construido de sí mismos, de los otros y del sistema en el que se inscriben. La legitimación de la ideología dominante, al realizarse mediante las instituciones, permite disimular la sujeción al estar al servicio de la sociedad, se perciben como natural sus prescripciones.

El discurso normalista, como el de cualquier grupo social, es producto de la formación que han recibido los sujetos en las instituciones y en la sociedad.

En una formación social no existe la ideología, sino diversas representaciones del mundo que responden a intereses de clase, grupos de poder que sostienen relaciones de tensión; Pêcheux apunta que en el seno de la formación social se da una formación ideológica:

Hablaremos de formación ideológica para caracterizar un elemento susceptible de intervenir, como fuerza confrontada a otras fuerzas, en la coyuntura ideológica característica de una formación social, en un momento dado; cada formación ideológica constituye así un conjunto complejo de actitudes y de representaciones que no son ni 'individuales' ni 'universales' sino que se refieren más o menos a posturas de clases en conflicto (Pêcheux, citado por Cros, 1986: 63).

Robin sostiene que "Estas formaciones ideológicas son complejos de actitudes y de representaciones referidas de manera inmediata a las diversas posiciones de clases en conflicto en un momento dado" (Robin, 1976: 7) es decir, en una coyuntura precisa.

En este punto cabe señalar que, en la práctica discursiva de los estudiantes normalistas en situación de entrevista, se revelan los posicionamientos ideológicos asumidos respecto de la práctica social de la educación y de los agentes que intervienen, al describir y narrar las experiencias en las prácticas docentes que desarrollan, así como la representación de lo que consideran es ser profesor. En el fragmento [3] que presentamos más adelante el normalista establece las prioridades 
de su práctica, apegadas al discurso de la modernidad que dio origen a la educación institucionalizada.

Robin (1976) indica que las prácticas discursivas, al ser prácticas sociales, se realizan bajo el influjo de una formación ideológica que implica modos de producción discursiva interrelacionados entre sí que determinan lo que puede ser dicho en una coyuntura específica; los Aparatos Ideológicos del Estado juegan un papel importante en su elaboración y difusión para la reproducción ideológica (Robin, 1976). Así, un profesor o, en nuestro caso, un estudiante normalista, puede explayarse en su discurso, pero siempre limitado por poderes sociales que le imponen censuras, tabúes o temores.

El modelo educativo neoliberal manifiesta su carácter ideológico al presentar sus principios y valores como naturales, racionales y como productos de la evolución histórica. En esto estriba su impacto en los profesores, además que éstos no reciben formación para la crítica y la investigación de las determinaciones de su práctica. Un indicador de ello es que en el corpus estudiado encontramos ausencia de estas temáticas, en ninguna de las 30 entrevista realizadas aparece cuestionamiento alguno acerca del origen del sistema escolar, sobre el lugar social del profesor o la construcción social de la figura del alumno, entre otros temas polémicos.

\section{FORMACIÓN DISCURSIVA Y EL JUEGO DEL INTERDISCURSO}

Foucault (2006: 62) define formación discursiva en términos de la regularidad que pudiera existir entre los elementos que componen un discurso, es decir, los objetos discursivos, formas de enunciación, los conceptos y elecciones temáticas, ya sea por el orden establecido, por sus correlaciones, funcionamientos o transformaciones.

Por su parte, Haroche, Henry y Pêcheux (citado por Cros, 1991: 64) definen y articulan las categorías formación discursiva y formación ideológica. Los autores establecen que FD es lo que puede y debe decirse; mediante el lenguaje, los enunciados, las formaciones ideológicas son representadas, Las formaciones ideológicas no son homogéneas, pueden contener una o más foramciones discursivas.

En la propuesta de Foucault (2006: 307), "saber" se refiere a lo que puede ser dicho en una práctica discursiva particular, misma que es determinada por la formación discursiva en la que se inserta; así, entre práctica discursiva y "saber" existe una relación de interdependencia; la formación discursiva también determina lo que se excluye del discurso o al menos se mitiga o atenúa. De esta manera, el discurso tiene el poder de interpelar a los sujetos pues en el uso de la lengua se asumen posturas ideológicas inscritas en las palabras, proposiciones, fórmulas o expresiones, que están siempre determinadas por el momento histórico en el que aparecen. No solo nos referimos a la elección de palabras, sino a las construcciones enunciativas, pues es en ese marco que adquieren significación.

El discurso mismo tiene inscrito un poder, ya sea el de interpelar al otro o de oponerse, resistirse o destruir el discurso del adversario. Para Foucault el poder es siempre relacional, no se puede hablar del poder en forma aislada. 
La actualización de preconstruidos, como constatamos en el discurso de los normalistas cuando citan a sus padres, maestros, profesores o agentes de medios de comunicación, entre otros, es una de las formas en que se materializa la interpelación. El poder del discurso, en su funcionamiento, radica en que el sujeto se hace responsable de lo ya dicho y "[...] este 'preconstruido' es el vehículo para los enunciados producidos por la "compleja totalidad dominante" de las formas discursivas" (Cros, 1991: 87), mismas que se inscriben en la complejidad de la formación ideológica.

Las formaciones discursivas no son homogéneas, de la misma manera que no lo son las formaciones ideológicas; se encuentran en relaciones de alianza, antagonismo o resistencia. Para Buenfil, "una misma entidad (es decir, ens o materialidad) puede estar discursivamente construida de diversas formas, dependiendo de la formación discursiva desde la cual se le nombra" (Buenfil, 1991: 183), ser profesor puede ser un guía, una autoridad y el poseedor de conocimientos en el marco de una formación discursiva, en otra formación, puede ser un facilitador o promotor de la competencia, en otra formación más, un actor político con la misión de transformar. En cada formación discursiva se agrupan objetos y actos en torno a una significación común (Buenfil, 1991: 182).

Es así como, en cada formación discursiva se teje un campo de saber, se constituye un poder, en el que se excluyen objetos o formas de enunciación, para construir una voluntad de verdad. En las prácticas discursivas se manifiestan regularidades que adquiere el lenguaje para enunciar la verdad. Ser profesor en la práctica discursiva normalista se funda en el saber-poder que surge del haz de relaciones que se establece entre las instituciones; procesos económicos, sociales, técnicas, tipos de clasificación, rituales, que dieron origen a la educación escolarizada.

A pesar de que la ideología neoliberal es la hegemónica en la formación social del capitalismo global, la interpelación no es plena puesto que otras posturas, inscritas en los preconstruidos, aún persisten y tienen influencia en la conformación de ser profesor, en la identidad docente y en las prácticas educativas cotidianas. En nuestro estudio, identificamos las marcas de la construcción del profesor pastor, producto de la escuela moderna, en relación de dominancia respecto de la racionalidad neoliberal de la educación y de sus agentes.

\section{Continuum posición tradicional - postura neoliberal sobre ser profesor}

El objeto discursivo ser profesor no tiene una significación intrínseca o inmanente, sino que su sentido es elaborado a partir del lugar que ocupa en una cadena discursiva, dado que entra en contacto con otros discursos o con otros elementos de un mismo discurso. Llegados a este punto, hemos presentado en forma general la discursividad de la ideología neoliberal, y se destaca el contraste con la configuración discursiva que en el discurso normalista hemos identificado.

La formación discursiva de la educación neoliberal, coexiste con la formación discursiva de la educación tradicional que construye una imagen del profesor como 
sacerdote-apóstol ${ }^{1}$, y que se hace presente por el interdiscurso. Haidar (2006) plantea el interdiscurso como una dimensión constitutiva de una formación discursiva, ya que la producción discursiva en una coyuntura específica retoma discursos anteriores, los repite, transforma, refuta, etcétera, y producen efectos de memoria.

La interdiscursividad puede ser sincrónica y diacrónica, de alianza o antagonismo, explícita o implícita. Las formulaciones previas presentes en el discurso estudiado, dan cuenta de las contradicciones constitutivas de toda formación social e ideológica

En el estudio que realizamos identificamos dos formaciones discursivas respecto de ser profesor que provienen de formaciones ideológicas diferentes y antagónicas. Por un lado, la formación discursiva de la ideología neoliberal, por el otro, la formación discursiva de la ideología de la llustración, éstas coexisten y se confrontan en las prácticas discursivas y en las no-discursivas que hemos señalado. Lo que puede y debe decirse respecto de ser profesor se materializa en el discurso normalista y dado que proviene de formaciones ideológicas y discursivas en relación de contradicción, el conflicto entre dos posiciones se hace presente, puesto que la construcción del objeto discursivo y las múltiples relaciones con otros objetos se conforman de maneras distintas.

El interdiscurso es el lugar de constitución de lo preconstruido, es decir, de construcciones anteriores que juegan un papel decisivo en la práctica discursiva.

Lo preconstruido remite así a las evidencias a través de las cuales el sujeto ve darse los objetos de su discurso: "lo que cada uno sabe" y simultáneamente "lo que cada uno puede ver" en una situación dada [...] "lo que cada uno conoce, puede ver o comprender", también es "lo que puede decirse" (Courtine, 1981: 36).

Determinar las condiciones de producción del discurso amerita analizar el interdiscurso de la formación discursiva que domina la secuencia discursiva. El discurso neoliberal sostiene: la flexibilización laboral, el profesor dinámico y facilitador del proceso de aprendizaje, la contribución de la educación en la producción de sujetos consumidores, aptos para el cambio y la convicción de que la opción de vida es lo transitorio, la responsabilidad docente del fracaso de la calidad educativa, la necesidad de eliminar los sindicatos o agrupaciones gremiales por ser agentes nocivos, la primacía del individualismo y de la concepción de la educación como mercancía, lograr la gobernabilidad de las personas mediante el uso de su libertad y el acendramiento de la empresa de sí, la ruptura con las tradiciones, la mercantilización de las relaciones, entre otras premisas (Laval y Dardot, 2013: 337 y 328); todo esto se teje en el discurso normalista con los preconstruidos que provienen de la formación discursiva que configura ser profesor como sacerdote-apóstol. El discurso normalista se caracteriza por las huellas profundas de este tipo de configuración en la identidad profesional que elaboran los futuros docentes; sin embargo, la ideología dominante de nuestro tiempo tiene su incidencia puesto que, desde las instituciones

${ }^{1}$ A partir de los aportes de Foucault (2008) identificamos que mediante los procesos de subjetivación vehiculizados por el Estado ser profesor es construido con base en dicho constructo. 
y desde prácticas no discursivas, también se ponen en marcha procesos de interpelación de los que podemos identificar sus marcas.

El objeto discursivo ser profesor se configura mediante los preconstruidos de las formaciones discursivas en juego en la coyuntura en la que el discurso es producido. Llegados a este punto, nos proponemos sintetizar y confrontar la incidencia de ambas formaciones discursivas.

De la perspectiva tradicional, que configura el profesor pastor, destaca el carisma del profesor como elemento esencial de su presentación ante los alumnos; su fuerza estriba en el componente emocional invertido en la relación que establece con ellos; sin embargo, es posible apreciar que el lugar asignado al profesor en la perspectiva neoliberal, a saber, de facilitador del aprendizaje, toma forma en el discurso de los normalistas, esta es una visión que prioriza la tarea de gestión de los profesores, y no solo para lograr los propósitos de eficiencia, reducción de los costos impuestos por las exigencias del mercado ${ }^{2}$ para ofrecer su producto y para su venta rentable. Ser profesor demanda de los normalistas la preparación de estrategias "divertidas", "llamativas", "motivantes", el uso de las nuevas tecnologías, para ganar la atención de los alumnos, en primera instancia, y como recurso para edificar autoridad, así como una imagen positiva.

El vínculo con el conocimiento es de reproducción, transmisión e instrumental, más que de un especialista en la disciplina, cualquiera que sea, incluso la pedagógica. La formación de profesores contribuye en el modelamiento descrito al no incluir en su currícula (SEP, 2000) cursos de investigación que favorezcan la reflexión sobre la práctica con miras a la generación de conocimiento, que se supone desarrollan las instituciones de educación superior.

El discurso neoliberal sobre la formación por competencias lo identificamos en el discurso normalista específicamente en lo relativo a la planeación didáctica:

[1] I: Porque nos dijo no, las planeaciones las está haciendo, las están haciendo, nada que ver con el plan / con el plan, el programa / dijo no están cumpliendo propósitos / así que él nos / él nos llevó a todos pero nos / puso una / una friega enorme / que comprendiéramos cómo se realizaban bien las planeaciones, de que viéramos los temas que tuvieran que concordar con el plan con los / aprendizajes esperados (E $1421 \mathrm{HP}){ }^{3}$

[2] I: En ese tiempo con las competencias que ahorita ya se cambiaron a... eh / no s, las competencias que ahorita ya... se reformaron por decirlo así (E 14 21HP).

Las prácticas prescritas en los planes y programas de estudio de educación secundaria son entendidas como adecuadas y deseables por los profesores de la Normal y por los estudiantes normalistas; al asumir como naturales dichas formas de hacer, se logra un auto gobierno que apunta a la realización de las tareas con pleno

\footnotetext{
${ }^{2}$ Si se considera, como lo hacen Laval y Dardot (2013), la educación como una mercancía sujeta a la oferta y la demanda.

${ }^{3}$ Como hemos mencionado anteriormente, las negritas indican los elementos de análisis.
} 
convencimiento. Por otra parte, el discurso de la calidad de la educación, de la necesidad de elevar la calidad educativa, es un punto nodal en la interpelación de los sujetos por parte de la ideología dominante.

Las instituciones imponen restricciones a la producción discursiva, es por ello necesario que la adhesión a las prescripciones académicas, didáctico-pedagógicas y las finalidades de la educación sean declaradas abiertamente.

La formación para el progreso, para formar la ciudadanía del futuro en las que se destacan valores y actitudes, son parte central en los fines que el futuro profesor se plantea como deseables, como se menciona en los siguientes fragmentos del corpus:

[3] I: Función primordial / pues en este caso sería / este, formar a... a esos ciudadanos no solo / que sean partícipes al, a... al hacer mejoras, hacer un mejor país, tener más / integrarlos a los valores / al cuidado del medio ambiente / a una... / una concepción de / de trabajo y responsabilidad / que estén preparados para cualquier cosa / no solamente / cumplir la educación básica por cumplirla por / por ser obligatoria / sino que para que ellos sepan que eso es una base / un cimiento para / terminar / con unos, con estudios para una mejor preparación, para que tengan / una buena, mejor / una calidad de vida mejor (E $0723 \mathrm{HU}$ ).

[4] I: Yo creo que la, e...I reto más importante del profesor es / que el alumno se interese por, por la educación que a m- que entienda o que entendamos también, uno como profesor / entienda que... que la educación es el único medio por el cual, que esta sociedad puede mejorar, puede cambiar para bien / entons el reto es que / el alumno quiera venir a la escuela o quiera educarse por / convicción propia, por, por gusto y no tanto por obligación (E $2422 \mathrm{HP}$ ).

Los normalistas se identifican con el discurso que da nacimiento a la escuela y cuyo postulado es la educación como fuente de progreso técnico industrial; al mismo tiempo se manifiesta una postura de resistencia al ideario neoliberal al poner de relieve la importancia de la misión de la escuela de fomentar los valores de la modernidad, en términos de Bauman (2007) "sólidos" que perduran en una sociedad en la que lo volátil y lo efímero, "líquido", se impone. En tanto agentes políticos, los futuros profesores asumen la tarea de gobernar a sus alumnos con la finalidad de lograr que ellos mismos se sometan a ciertas normas. La reproducción ideológica se realiza por medio de la comunicación que los normalistas sostienen con los estudiantes y las prácticas rituales que se desarrollan en la escuela.

Los normalistas realizan prácticas docentes en las escuelas secundarias, lo cual les permite conocer las prácticas cotidianas de los profesores en servicio, directivos, alumnos, padres de familia, entre otros actores, y a partir de ello elaboran su saber sobre ser profesor. Mediante los relatos de sus experiencias dan cuenta de la resistencia al discurso que demerita la figura del profesor, que proviene de diversas fuentes: de las esferas altas del propio Aparato Ideológico que constituye la Escuela, de los medios de comunicación, de los padres de familia y de la sociedad en general. Ante las deficiencias que esas instancias destacan de los docentes, los normalistas presentan su capital simbólico, su vocación, la entrega y la gratuidad, como garantes de su profesionalidad; por ejemplo en el siguiente testimonio: 
[5] I: Qué significa ser profesor // bueno para empezar s- sí es entrega en cuanto a... a que te guste el trabajo / porque an- a, digo pues escuchas a toda la gente de que jah! ser maestro nada más trabajas medio día / y no es cierto realmente ser maestro no es nada más trabajar medio dí...a o / $\mathrm{o}$, o sea de pasadita, porque / te llevas trabajo a tu casa / no revisas eh, en, este, en la escuela tienes que preparar clase para la siguiente día / y pos a, también acordarte que tú, el arte de la formación de un muchacho / que mucho de lo que tú les enseñas v'a repercutir / este, pos para el resto de su vida y / ¿qué pienso de ser maestro? que es una labor muy, muy complicada / que yo creo que lo único / que la única persona que entiende qué es ser maestro es el propio maestro (E29 27MU).

En [5], el informante habla de las actividades que un profesor lleva a cabo más allá de su horario laboral para enfrentar las críticas vertidas por el colectivo, que es, muchas veces, "toda la gente".

Las tradiciones escolares siguen presentes en el discurso y en las prácticas de los normalistas ${ }^{4}$; los rituales tales como las ceremonias cívicas, la formación diaria, los tiempos destinados a las evaluaciones, el uso del uniforme, la disposición del espacio áulico e incluso las festividades de diversa índole, forman parte de las opciones incuestionables de ser profesor.

La fuerza del interdiscurso que actualiza la figura del profesor pastor, tiene su origen en la memoria colectiva, transmitida por generaciones, especialmente de padres con formación docente, y fortalecida por las experiencias escolares; sin embargo, advertimos su debilitamiento ante el poderío del discurso neoliberal que refuerza cada vez más una imagen de inoperancia y poca eficacia de la labor de los profesores. Esta imagen es promovida por los medios de comunicación, especialmente por empresas como Televisa y organizaciones como Mexicanos Primero ${ }^{5}$.

El control discursivo que se realiza desde las instituciones, así como el ejercicio del poder mediante prácticas no discursivas, pero con fuerte valor simbólico, mina la adhesión gremial en torno al sindicato. Consideramos que este es un punto importante en la definición de ser profesor, puesto que, de ser un aspecto sustancial durante el siglo XX, ahora se le toma distancia o se le rechaza abiertamente. Como señalamos en apartados anteriores, uno de los aspectos a atender por las políticas neoliberales es disminuir la fuerza sindical, y favorecer la flexibilidad laboral en el campo educativo para reducir los costos, lo cual se ha logrado con la puesta en marcha de la reforma educativa en nuestro país. Este último propósito conlleva la implementación de un sistema de evaluaciones docentes que ha implicado transformaciones en las prácticas de gestión escolar y académica, a la cual los profesores se han sometido,

\footnotetext{
${ }^{4}$ Desde la Secretaría de Gobernación se emiten lineamientos para llevar a cabo las ceremonias cívicas (véase: http://ceremoniascivicas.segob.gob.mx/es/Desarrollo_Politico/Programas_Ceremonias).

${ }^{5}$ Por ejemplo, "De Panzazo" (2012) es un ejemplo de los esfuerzos que Televisa ha realizado para difundir una imagen negativa de la educación y sus profesores en México. Se trata de un documental dirigido por Juan Carlos Rulfo y Carlos Loret de Mola y patrocinado por integrantes de la organización empresarial Mexicanos Primero.
} 
pero oponiendo resistencia y crítica; una reforma laboral cuya máscara es decir que es una reforma educativa también, por ello, ha sido cuestionada por el sector intelectual de nuestro país, entre ellos Enrique Graue, actual rector de la UNAM, por citar un ejemplo. Sus críticas se han vertido en diversos medios de comunicación ${ }^{6}$.

A pesar de que la Reforma Educativa no es plenamente aceptada, los docentes acuden a las evaluaciones pues corren el riesgo de perder su trabajo. De acuerdo con Díaz-Barriga (2015), la evaluación docente contenida en la Reforma es ante todo un tema político: "La intención ha sido siempre evaluar a los maestros para poder correrlos. Aunque formalmente se hable de la calidad de un buen docente, en realidad el tema central es que la evaluación habilita al gobierno para despedir profesores ${ }^{\prime \prime}$. No es fortuito que se haya tomado en cuenta a la clase empresarial, en particular Mexicanos Primero, y no a los profesores.

En el corpus encontramos referencias a la Reforma Educativa, presentamos un ejemplo para ilustrar:

[6] I: Vien- vien- viene precisamente de lo / de lo que actualmente estamos viviendo que en este caso son las reformas laborales y educativas, viene... precisamente de eso de ahí ra- de ahí radica donde los maestros ya tienen cierto temor a seguir avanzando, a seguir / a seguir luchando por, por algo que a ellos les gusta hacer / y / y no lo, precisamente no lo dejan / no lo dejan por una cuestión personal de que / bueno ya no me siento completo para ser maestro sino simplemente que lo / lo están dejando, sienten que / van a ver afectados sus derechos como / como trabajador / a pesar de que las leyes no son retroactivas aquí marcan, marcan artículos donde si pueden ser retroactivas, pueden hacer daño / pues bueno a las personas que ya tienen, tienen / tienen tiempo trabajando como maestros y / y nosotros que apenas vamos comenzando / bueno pues no hay otra o... / o que nos aliniemos a esa, a esa / a esa reforma o / o tratar de buscar por otro lado (E $3125 \mathrm{HN})$.

En 2013, año en que realizamos esta entrevista, se aprobó la Reforma Educativa y los efectos se hicieron patentes de forma inmediata. En los discursos estudiados en esta tesis, los normalistas perciben que la Reforma es de carácter laboral y que en el futuro les resultará en perjuicio al querer insertarse en el campo de trabajo, esta es una situación a la que deben someterse al percibir que el poder que se ejerce sobre los profesores es difícil de combatir. A pesar de ello, el sentido crítico de las condiciones sociales está presente en el discurso de los normalistas al poner en tela de juicio la efectividad de las reformas.

[7] I: (...) dices tú no es / no es algo nuevo [los problemas básicos de lectura] / es algo que viene desde / desde hace mucho / ¿cuántos años? no tengo idea / pero sí se vino presentando desde hace mucho y lalamentablemente no se pueden corregir / cambian las / las planecio¿cómo le llaman? los programas / han habido reformas y todo pero / no se

\footnotetext{
${ }^{6}$ Véase un ejemplo en: http://www.elfinanciero.com.mx/nacional/reforma-educativa-esta-porverse-enrique-graue.html.

${ }^{7}$ Recuperado de: http://www.iisue.unam.mx/boletin/?p=1157.
} 


\section{cambia / quizá sea conveniente que el pueblo / ija! el pueblo no comprenda (risas E) / a quizás a alguien le conviene ¿no? (E 08 28MT).}

En la secuencia discursiva el informante encadena los cambios en programas de estudio y planeaciones que se derivan de las reformas educativas con los bajos resultados que se han alcanzado y alude con ironía a un interés oculto ${ }^{8}$. En las últimas líneas, el informante cuestiona la existencia de sectores cuyo interés es dejar al pueblo en la ignorancia ("quizá sea conveniente que el pueblo / ija! el pueblo no comprenda").

Las formaciones discursivas, la tradicional y la neoliberal, determinan lo que puede y debe ser dicho; establecen relaciones de contradicción respecto de ser profesor y, por ello, generan tensión en la práctica discursiva de los normalistas al confrontar la imagen idealizada que proviene del discurso tradicional, con la que actualmente en el discurso neoliberal se les presenta a los profesores como deseables.

Con Pêcheux (1978) se confirma que la formación social, la formación ideológica y la formación discursiva inciden en las formaciones imaginarias, que los normalistas se hacen de sí mismos, de los referentes que construyen y de los demás.

\section{FORMACIONES IMAGINARIAS: SER PROFESOR Y LOS NORMALISTAS}

En este documento se ha trabajado categorías que se sitúan en un nivel macro, formación social, formación ideológica y formación discursiva. Ahora nos situamos en el nivel más subjetivo y particular de las condiciones de producción del discurso, retomando los aportes de Pêcheux (1978) acerca de las formaciones imaginarias que operan en la producción discursiva.

Pêcheux (1978) plantea que los discursos institucionales deben seguir las formas establecidas por la institución; en el caso del discurso educativo es preciso destacar que se deben tomar en cuenta diversos niveles de los discursos institucionales, es decir, considerar, por ejemplo, el nivel jurídico-político en los documentos que rigen la política educativa, nivel que se vierte en el plan de estudios, emitido por los funcionarios educativos, pero también que surgen del profesorado. En cada lugar (ya sea un sujeto singular o colectivo), la facultad para tomar la palabra, las temáticas y las formas responden al discurso institucional dictado por quienes ocupan las posiciones en la cúspide de poder, desde las jerarquías sociales.

El autor define las formaciones imaginarias ( $\mathrm{Fl}$ ) como elementos estructurales de las condiciones de producción de los discursos que designan el lugar que el productor del discurso (A) y el receptor (B) del mismo se atribuyen a sí mismo y al otro, y al referente $(\mathrm{R})$, o sea el objeto discursivo que no pertenece a la realidad física (Pêcheux, 1978: 48). La hipótesis que plantea Pêcheux es que los lugares A y B están representados en los procesos discursivos, pero sus rasgos objetivos son transformados, porque en "toda formación social existen reglas de proyección que establecen las relaciones entre las situaciones (objetivamente definibles) y las posiciones (representaciones de estas situaciones)" (Pêcheux, 1978: 49). Dichos lugares no son

8 Flores (2008 y 2013) realiza un estudio profundo de la ironía en el Habla de Monterrey. El lector encontrará en sus textos una investigación amplia sobre esta figura literaria. 
azarosos, responden a las posiciones que en una formación social son proyectadas y asumidas por los sujetos.

Por otro lado, lo que se dice no siempre tiene el mismo valor ni la misma fuerza, esto dependerá de las condiciones en que el discurso es producido y del lugar que ocupe el emisor. Los sujetos del discurso que aquí se estudian están inscritos en una relación de fuerzas entre elementos antagónicos que provienen de las formaciones discursivas que hemos abordado en el apartado anterior.

Pêcheux (1978) propone el análisis de las formaciones imaginarias en el siguiente cuadro:

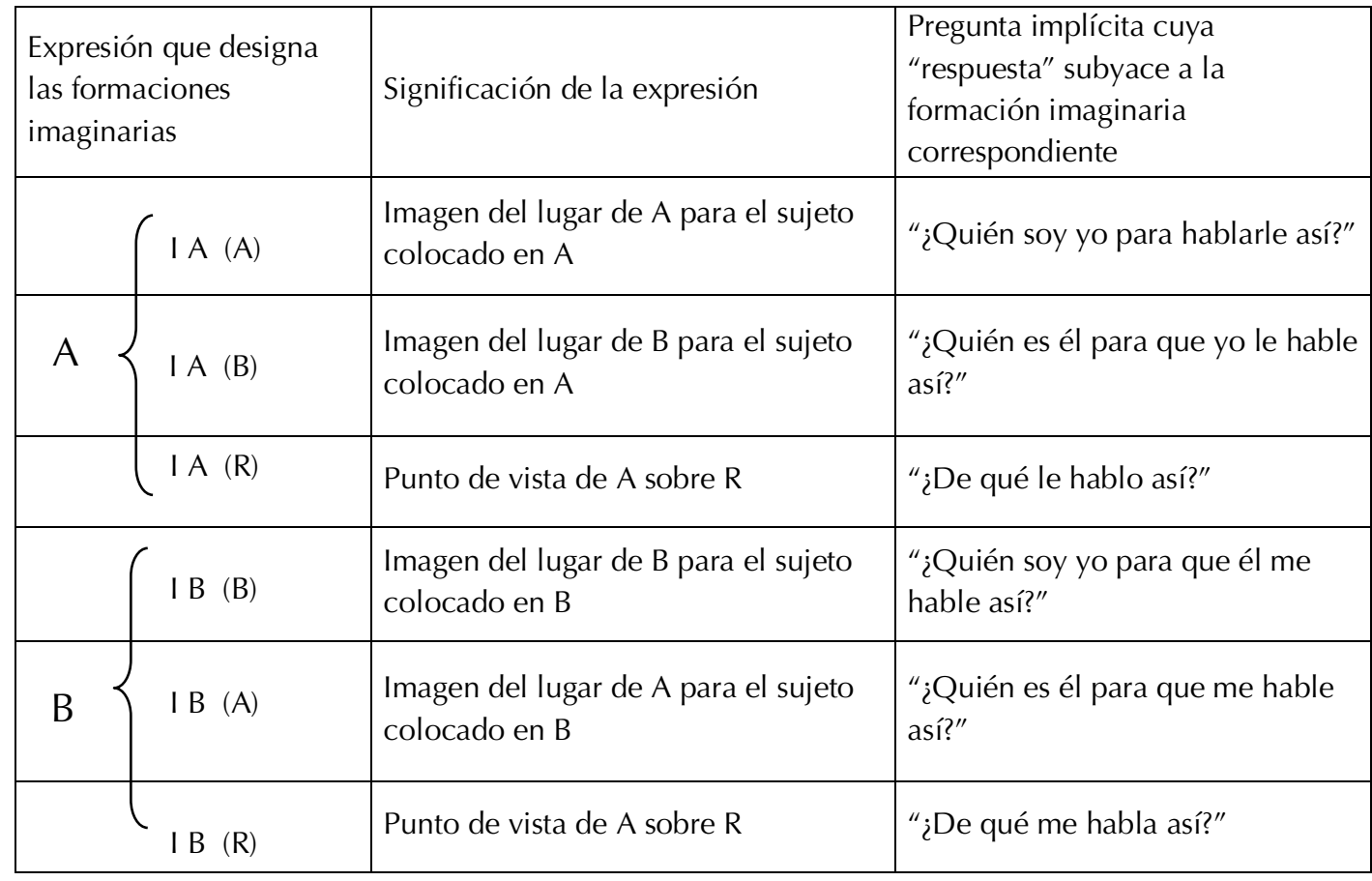

Cuadro 2.1. Formaciones imaginarias (reproducción de Pêcheux, 1978: 49-50)

Otra dimensión del discurso se plantea en torno a que la producción discursiva supone, por parte del emisor, una anticipación de las representaciones del receptor, y que con base en ellas elabora las estrategias discursivas que pondrá en juego. Expuesto a continuación.
$A\left\{\begin{array}{l}I_{A}\left(I_{w}[A]\right) \\ I_{s}\left(I_{n}[B]\right) \\ I_{A}\left(I_{n}[R]\right)\end{array}\right.$
$B\left\{\begin{array}{l}\mathrm{I}_{\mathrm{a}}\left(\mathrm{I}_{A}[\mathrm{~A}]\right) \\ \mathrm{I}_{\mathrm{a}}\left(\mathrm{I}_{\star}[\mathrm{B}]\right) \\ \mathrm{I}_{\mathrm{s}}\left(\mathrm{I}_{A}[\mathrm{R}]\right)\end{array}\right.$

Cuadro 2.2. Formaciones imaginarias anticipadas (reproducción de Pêcheux, 1978: 50-51) 
Las anticipaciones preceden a las respuestas que B pudiera hacer, que sancionan las decisiones anticipadoras de A. Las anticipaciones que hace A sobre B dependen de la distancia que $A$ supone entre $A$ y $B$.

Coincidimos con Pêcheux (1978) en que las diversas formaciones imaginarias resultan de procesos discursivos anteriores que surgen de otras condiciones de producción, las cuales han dejado de funcionar pero que originan tomas de posición implícitas. Dirá el autor que la sustancia de las formaciones imaginarias es lo "ya oído" o lo "ya dicho", de los conocimientos que el sujeto posee y presenta a su interlocutor (Pêcheux, 1978: 52).

Como se observa en el esquema, las formaciones imaginarias son varias para cada elemento (A, B, R), e incluso contradictorias, porque derivan de las formaciones ideológicas y discursivas en las que los sujetos se ven implicados.

En esta investigación, de acuerdo con los objetivos planteados, situamos el análisis de las formaciones imaginarias en:

$\mathrm{I}_{\mathrm{A}}(\mathrm{R})$ ¿Qué imagen tiene A del objeto discursivo ser profesor? En A ubicamos al normalista entrevistado pues es de interés central para nuestra investigación su producción discursiva acerca de este objeto discursivo.

$\mathrm{I}_{\mathrm{A}}(\mathrm{A})$ ¿Quién soy yo para hablarle así? Delineamos la forma en que los sujetos informantes se ven a sí mismos al abordar el tema de la docencia y de ser profesor.

$\mathrm{I}_{A}\left(\mathrm{I}_{B}[R]\right)$ ¿Qué imagen tiene $A$ de lo que $B$ tiene de $R$ ? Consideramos pertinente tener en cuenta esta formación imaginaria en el análisis porque los informantes elaboran con anticipación una imagen de lo que para su interlocutor significan los temas abordados en la entrevista ${ }^{9}$. Cabe señalar que la entrevistadora tuvo contacto, directo o indirecto, con todos los participantes antes de las entrevistas, pues durante la formación ocupó cargos académico-administrativos y de algunos de ellos fue profesora de alguna asignatura. Esta situación influye en la forma en que los sujetos, en la situación de entrevista, elaboran su discurso, puesto que es con una maestra de la institución ante quien reconstruyen el referente de ser profesor.

En referencia al posicionamiento de los normalistas, estos se encuentran en el nivel más bajo de la escala jerárquica de poder, y sometidos a un plan de formación que no está sujeto a sus preferencias, sin embargo, eso no quiere decir que estén desprovistos de autoridad. Al dejarles la palabra, los alumnos no solo pretenden persuadir, sino también reclamar o denunciar.

En cuanto al referente que se aborda en la interacción discursiva de alumnos y profesores, el capital cultural que se ofrece en la formación profesional a través de las Escuelas Normales está determinado por el Estado; al no ser una profesión libre, éste establece los lineamientos y las reglas del juego en el campo de la formación de profesores; el Estado posee, de acuerdo con Bourdieu (1997: 99), un metacapital con po-

${ }^{9}$ La distancia social entre los interlocutores influye en la forma en que el informante se presenta a sí mismo y a los objetos discursivos. 
der sobre el resto de los diferentes tipos de capital, al tener a su servicio a los agentes del campo que poseen no solo mayor capital cultural, también político y económico.

¿Quién soy yo para hablarle así? En general los normalistas se presentan a sí mismos como sujetos dignos de tomar la palabra para abordar lo referente a ser profesor, su práctica, sus saberes. Lo hacen con autoridad, con base en el saber que les da la práctica directa en las aulas y con el respaldo de una larga tradición que sitúa al profesor en un lugar social valorado, al cuidado de los futuros ciudadanos. A partir de esta postura cuestionan el estado de cosas existentes en relación con el campo laboral: la ocupación de plazas docentes por quienes no cuentan con formación normalista y por profesores que ingresan al magisterio o se mantienen aun trabajando por un salario y prestaciones que hasta ese momento se daban o se sostenían (en el año 2013); puede verse por ejemplo en el corpus [8]:

[8] I: Yo creo que se requiere más que nada / que a uno le guste la carrera / porque sí muchas veces / como anteriormente se decía que la Normal, la Normal Superior Básica, que era muy fácil que te metías, que eras maestro, te pagaban, tenías muchas vacaciones / yo creo que much- esto... se abrió mucho a que personas que ni siquiera querían ser maestros, que nada más querían alguna carrera para trabajar / se metieran a eso, se meterían como maestros porque ps es fácil / piensan que es muy fácil, que nada más / eh... les das trabajo a los niños durante todo el día y ya / y te pagan muy bien y tienes vacaciones, yo creo que esto abrió mucho a que / surgieran mucho ese tipo de maestros / porque en realidad no / no les gusta la profesión simplemente por querer trabajar en algo, ganar algún dinero ( $E$ $1421 \mathrm{HP})$.

Otra fuente de inconformidad y de tensión es identificada en las condiciones en que realizan su trabajo los docentes, en la que destaca la falta de reconocimiento social promovida y difundida por los propios agentes de la educación. En otro fragmento del corpus [9], el normalista enfoca a los padres de familia que actualmente restan autoridad a los profesores:

[9] I: (...) como entonces le menciono, el padre de familia se pone del lado del / de su hijo, del hijo sí del / del alumno y viene y le reclama a los maestros / eh... cuando yo siento que en mis tiempos, en mi caso personal pues era diferente / era muy diferente, mis padres / o sea de que les mandaban llamar, eh, no es que su hijo hizo tal travesura / y... no maestro, no perdón, yo hablo, voy a hablar con él / para si lo voy a castigar o algo / eh, no pero usted si lo ve que anda haciendo travesuras regáñelo y todo / entonces ahí yo siento que en aquellos tiempos / o sea el maestro es maestro y el maestro dice oye es que está haciendo esto, no está entregando tareas, está nada más jugando / o algo / eh... el padre de familia se ponía del lado del maestro y decía ah, okay, está bien yo voy a hablar con él, lo voy a / o sea regañarlo en su s, si es necesario (Entrevista 017 27HP).

¿Qué imagen tiene el sujeto del objeto discursivo? El punto de vista de los normalistas sobre ser profesor se decanta por la perspectiva tradicional que denominamos profesor-pastor, al atribuirle características de protector, guía; cuyos valores, actitudes $y$ fines son dispuestos en torno a sus alumnos a quienes prefiguran como 
sujetos con necesidad de ser enseñados y guiados, para lograr su inserción en la sociedad, en el mundo laboral y académico; un ejemplo es el fragmento [3]. Sin embargo, paradójicamente, se percibe un creciente empoderamiento de los alumnos de secundaria, favorecido por la familia, los medios de comunicación y la sociedad en general, que le ha concedido poderes al alumnado para dominar la relación que establece con el profesor, como en el discurso citado anteriormente [9].

El entramado complejo y contradictorio de "lo ya oído" y "lo ya dicho", las formaciones imaginarias sobre ser profesor y sobre sí mismos, que se manifiestan en la práctica discursiva de los normalistas, muestran tensiones en relación con diferentes dimensiones: de las prácticas sindicales, que actualmente son rechazadas o al menos cuestionadas por ser símbolo de corrupción, de la responsabilidad del descuido de su tarea primordial, o la atención a los alumnos; por otra parte, de la dimensión de la profesionalización que cuestiona el saber de los profesores normalistas; además, la que confronta el imaginario del profesor como fuente de saber y poder con el desprestigio del que son objeto en la actualidad. Para los normalistas hay un antes y un ahora, que los conmina a una reelaboración continua sobre quiénes son y quiénes serán como profesores en un mundo en constante cambio y del que advierten amenazas a partir de las políticas educativas adoptadas.

\section{CONCLUSIONES}

Ser profesor se configura en una red de tensiones que resultan de las relaciones entre formaciones discursivas contradictorias que inciden en la formación de la identidad profesional. Las narrativas que subyacen y dan vida al discurso normalista procedentes de la vida familiar, de las experiencias escolares propias, del discurso oficial plasmado en el plan de estudio, así como las que provienen directamente de los padres de familia, los alumnos y los medios de comunicación, no son unívocas, son heterogéneas. Por un lado, ser profesor es valorado y reconocido socialmente, representación anclada en los valores universales (mismos que debe perpetuar), en la estabilidad social y laboral, pleno de certezas sobre su lugar en el mundo y de los fines de su actuación. A partir de esta visión los normalistas se configuran y reconfiguran, para enfrentar los embates de ser profesor, y que se registran en las otras versiones devaluadas de la profesión docente que son elaboradas desde los agentes del mismo aparato escolar en complicidad con otros agentes que las difunden y las fortalecen.

La influencia de la coyuntura en el discurso obliga al uso de ciertas palabras para construir el ser profesor por parte de los normalistas: vocación, entrega, valores, progreso; además, competencias, uso de tecnologías, evaluación docente, pero con menos intensidad que las primeras; vertientes que expresan las formaciones ideológicas de las que se desprenden campos de poder-saber que configuran al sujeto del discurso: el normalista, futuro profesor. En ese sentido, se expresan opciones políticas divergentes. La ideología y el poder se materializan en el discurso que en esta investigación nos ocupa. 


\section{BIBLIOGRAFÍA}

Bauman, Zygmunt. (2007). Tiempos líquidos. México: FCE.

Buenfil, Rosa. (1991). "Análisis de discurso y educación", consultado: 03 de enero de 2015, en http://www.uv.mx/blogs/uvi/files/2008/10/unidad-3 2buenfil.doc.

Bourdieu, Pierre. (1997). Razones prácticas. Sobre la teoría de la acción. Barcelona: Anagrama.

Courtine, Jean-Jacques. (1981). "Análisis del discurso político", Consultado el 18 de marzo de 2017, Langages. Núm. 62. París, Didier/Larousse, Scribd, en https://es.scribd.com/document/342310681/COURTINE-J-j-Analisis-Del-DiscursoPolitico

Cros, Edmond. (1991). "En torno a la interdiscursividad", en: Malcuzynski, M. Pierrette (Editor y coordinador) (1991). Sociocríticas practicas textuales: cultura de fronteras. Amsterdam: Ed. Rodopi, B. V.

— (1986). Literatura, ideología y sociedad. Madrid: Gredos.

Flores, María. (2008). Función poética del lenguaje: la ironía en el habla de Monterrey (1985-1986). Monterrey: Universidad Autónoma de Nuevo León.

- (2013). Flores, M. (2013). "Ironización y atenuación en El Habla de Monterrey PRESEEA". Consultado el 20 de enero de 2017, Repositorio UANL, en http://eprints.uanl.mx/11906/1/Memoria-en-extrenso-ironización.PDF.

Foucault, Michel. (1996). Vigilar y castigar. México: Siglo XXI.

— (2006). La arqueología del saber. México: Siglo XXI.

— (2008). Tecnologías del Yo. Buenos Aires: Paidós.

Haidar, Julieta. (2006). Debate CEU-Rectoría. Torbellino pasional de los argumentos. México: UNAM.

Laval, Christian. y Dardot, Pierre. (2013). La nueva razón del mundo. Ensayo sobre la sociedad neoliberal. España: Gedisa.

Pêcheux, Michel. (1978). Hacia el análisis automático del discurso. Madrid: Gredos.

Puiggrós, Adriana. (1996). "Educación neoliberal y quiebre educativo". Nueva Sociedad. No. 146, Noviembre-Diciembre, pp. 90-101.

Robin, Regine. (1976). "Discourse politique et conjuncture", en: L'analise du discourse. Montreal: Centre Educatif et culturel.

\section{FUENTES ELECTRÓNICAS S/A O S/F:}

Secretaría de Gobernación. "Guía de Ceremonias Cívicas de Izamiento, Incineración y abanderamiento". Consultado: 13 de agosto de 2015, en http://ceremoniascivicas.segob.gob.mx/es/Desarrollo_Politico/Programas_Ceremonias. 
León, Mariana. (2015). "Graue ve 'faltantes' en reforma educativa". El financiero, consultado: 10 de diciembre de 2015, en: http://www.elfinanciero.com.mx/nacional/reforma-educativa-esta-por-verse-enrique-graue.html.

Instituto de Investigaciones sobre la Universidad y la Educación (2015). “Qué opinan los expertos sobre la Evaluación?". Consultado: 10 de diciembre de 2015, en http://www.iisue.unam.mx/boletin/?p=1157.

\section{LARGOMETRAJES}

Rulfo, J. y Loret de Mola, C. (Directores); Alatorre, D. (Productor) (2012). De Panzazo [Documental]. México: Mexicanos Primero / La Nueva Luna. 